Eskes, C., Boström, A.-C., Bowe, G. et al. (2017). Good cell culture practices \& in vitro toxicology. Toxicol In Vitro 45, 272277. doi:10.1016/j.tiv.2017.04.022

Gstraunthaler, G. and Hartung, T. (1999). Bologna declaration toward good cell culture practice. Altern Lab Anim 27, 206.

Hartung, T., Balls, M., Bardouille, C. et al. (2002). Report of ECVAM task force on good cell culture practice (GCCP). Altern Lab Anim 30, 407-414. doi:10.1177/026119290203000 404

Hartung, T., de Vries, R., Hoffmann, S. et al. (2019). Toward good in vitro reporting standards. ALTEX 36, 3-17. doi:10.14573/ altex.1812191

Krebs, A., Waldmann, T., Wilks, M. F. et al. (2019). Template for the description of cell-based toxicological test methods to allow evaluation and regulatory use of the data. ALTEX 36, 682699. doi:10.14573/altex.1909271

Marx, U., Andersson, T. B., Bahinski, A. et al. (2016). Biology-inspired microphysiological system approaches to solve the prediction dilemma of substance testing using animals. ALTEX 33, 272-321. doi:10.14573/altex.1603161
Marx, U., Akabane, T., Andersson, T. B. et al. (2020). Biology-inspired microphysiological systems to advance medicines for patient benefit and animal welfare. ALTEX 37, 365-394. doi:10.14573/altex.2001241

OECD (2005). Guidance Document on the Validation and International Acceptance of New or Updated Test Methods for Hazard Assessment. OECD Series on Testing and Assessment, No. 34. http://bit.ly/24oFedN

OECD (2018). Guidance Document on Good In Vitro Method Practices (GIVIMP). OECD Series on Testing and Assessment, No. 286. OECD Publishing, Paris. doi:10. 1787/9789264304796-en

Pamies, D., Bal-Price, A., Simeonov, A. et al. (2017). Good cell culture practice for stem cells and stem-cell-derived models. ALTEX 34, 95-132. doi:10.14573/altex.1607121

Pamies, D., Bal-Price, A., Chesné, C. et al. (2018). Advanced good cell culture practice for human primary, stem cellderived and organoid models as well as microphysiological systems. ALTEX 35, 353-378. doi:10.14573/altex.1710081

\title{
Corrigendum
}

\section{Corrigendum to An Advanced In Vitro Model to Assess Glaucoma Onset}

\author{
Sergio C. Saccà 1, Sara Tirendi2,3, Sonia Scarfì 4, Mario Passalacqua², Francesco Oddone ${ }^{5}$, Carlo E. Traverso ${ }^{1,6}$, \\ Stefania Vernazza ${ }^{5 \#}$ and Anna M. Bassi2,3\# \\ ${ }^{1}$ IRCCS, San Martino General Hospital, Ophthalmology Unit, Genoa, Italy; ${ }^{2}$ Department of Experimental Medicine (DIMES), University of Genoa, \\ Genoa, Italy; ${ }^{3}$ Inter-University Center for the Promotion of the 3Rs Principles in Teaching \& Research (Centro 3R), Italy; ${ }^{4}$ Department of Earth, \\ Environmental and Life Sciences (DISTAV), University of Genoa, Genoa, Italy; ${ }^{5}$ IRCCS-Fondazione Bietti, Rome, Italy; ${ }^{6}$ Eye Clinic of Genoa, \\ San Martino General Hospital, Department of Neuroscience, Rehabilitation, Ophthalmology, Genetics, Maternal and Child Health (DiNOGMI), \\ University of Genoa, Genoa, Italy
}

In this manuscript, which appeared in ALTEX 37, 265-274 (doi: 10.14573/altex.1909262), the affiliation of Stefania Vernazza should read:

Stefania Vernazza ${ }^{\text {\# }}$

${ }^{5}$ IRCCS-Fondazione Bietti, Rome, Italy

and the address for correspondence should read:

\footnotetext{
Stefania Vernazza, PhD,

IRCCS, Fondazione Bietti

via Livenza 3, 00198 Rome, Italy

(stefania.vernazza@yahoo.it).
}

doi:10.14573/altex.1909262e 